\title{
HUBUNGAN MUTU PELAYANAN KESEHATAN DENGAN KEPUASAN PASIEN PESERTA BPJS DI UNIT RAWAT INAP PUSKESMAS CIBUNGBULANG KABUPATEN BOGOR TAHUN 2018
}

\author{
Lisna Maulina $^{1)}$, T. Abdul Madjid ${ }^{2)}$, Indira Chotimah ${ }^{3)}$ \\ ${ }^{1)}$ Konsentrasi Manajemen Pelayanan Kesehatan (MPK), Program Studi Kesehatan Masyarakat Fakultas Ilmu \\ Kesehatan, Universitas Ibn Khaldun Bogor \\ Email : lisnamaulina9@gmail.com \\ ${ }^{2)}$ Konsentrasi Manajemen Pelayanan Kesehatan (MPK),Program Studi Kesehatan Masyarakat Fakultas Ilmu \\ Kesehatan, Universitas Ibn Khaldun Bogor \\ Email: abd.madjid@uika-bogor.ac.id \\ ${ }^{3)}$ Konsentrasi Manajemen Pelayanan Kesehatan (MPK),Program Studi Kesehatan Masyarakat Fakultas Ilmu \\ Kesehatan, Universitas Ibn Khaldun Bogor \\ Email : indira.chotimah@gmail.com
}

\begin{abstract}
Abstrak
Kepuasan pasien adalah tingkat perasaan pasien yang timbul sebagai akibat dari kinerja pelayanan kesehatan yang diperolehnya setelah pasien membandingkan dengan apa yang diharapkannya. Service quality yang tinggi merupakan faktor terpentingnya agar tercapainya mutu pelayanan kesehatan di Puskesmas Cibungbulang Kabupaten Bogor. Tujuan penelitian ini untuk mengetahui hubungan mutu pelayanan kesehatan dengan kepuasan pasien di instalasi rawat inap. Penelitian ini menggunakan metode kuantitatif dengan desain penelitian cross sectional. Sampel yang diambil menggunakan teknik purposive sampling didapatkan 1,864 pasien di instalasi rawat inap. Intrumen penelitian menggunakan kuesioner. Data dianalisis mengunakan uji statistik Chi Square dengan tingkat kemaknaan $p$-value $\leq 0,05$. Lokasi penelitan dilakukan pada Puskesmas Cibungbulang. Hasil penelitian ini menunjukan bahwa faktor tangible ( $p$-value $=0,125)$, faktor reliability ( $\mathrm{p}$-value $=0,285$ ), dan faktor assurance (p-value $=0,702$ ) tidak terdapat hubungan dengan kepuasan pasien di puskesmas cibungbulang. Sedangkan faktor responsiveness ( $\mathrm{p}$-value $=0,000$ ) dan faktor empathy (p-value $=0,000$ ) terdapat hubungan dengan kepuasan pasien di puskesmas cibungbulang.
\end{abstract}

\section{Kata kunci : Kepuasan Pasien, Tangible, Reliability, Assurance, Responsiveness, Empathy}

\section{PENDAHULUAN}

Peraturan Menteri Kesehatan Nomor

75 Tahun 2014 tentang Puskesmas menyebutkan bahwa puskesmas adalah fasilitas pelayanan kesehatan yang menyelenggarakan upaya kesehatan masyarakat dan upaya perseorangan tingkat pertama, dengan lebih mengutamakan upaya promotif dan preventif, untuk mencapai derajat kesehatan masyarakat yang setinggitingginya diwilayah kerjanya. Apabila pelayanan kesehatan yang bermutu dapat diselenggarakan, maka akan dapat 
memperkecil timbulnya resiko akibat penggunaan berbagai kemajuan ilmu dan teknologi tetapi sekaligus juga akan dapat memenuhi kebutuhan dan tuntutan masyarakat yang semakin hari tampak semakin meningkat. Salah sau penyediaan pelayanan kesehatan yang mempunyai peran sangat penting dalam memberikan pelayanan kesehatan kepada masyarakat adalah puskesmas.

Menurut WHO (World Health Organization) menyebutkan bahwa semua negara di dunia harus memperkuat sistem pelayanan kesehatan primer untuk meningkatkan efektivitas (kesehatan masyarakat yang lebih baik), efisiensi (biaya tetap dikelola), ekuitas (kesempatan yang sama untuk mendapatkan pelayanan kesehatan yang sesuai) dan sistem perawatan kesehatan berkelanjutan.

Berdasarkan data Profil Kesehatan Indonesia (2016), Jumlah puskesmas di Indonesia sampai dengan Desember 2016 adalah 9.767 unit, yang terdiri dari 3.411 unit puskesmas rawat inap dan 6.356 unit puskesmas non rawat inap. Jumlah ini meningkat dibandingkan tahun 2015 yaitu sebanyak 9.754 unit, dengan jumlah puskesmas rawat inap sebanyak 3.396 unit dan puskesmas non rawat inap sebanayak 6.358 unit. Jumlah peserta BPJS terus meningkat setiap tahunnya, pada tahun 2017 sebanyak 176.931.515 jiwa sudah terdaftar menjadi peserta BPJS di Indonesia (BPJS

\section{METODE}

Jenis penelitian ini adalah penelitian kuantitatif dengan desain analisis deskriptif dengan pendekatan cross-sectional. Penelitian cross- sectional meneliti suatu kejadian satu waktu sekaligus pada waktu yang sama. Peneliti ini bertujuan untuk mendapatkan hubungan mutu pelayanan
Kesehatan,2017).

Menurut data dari Dinas Kesehatan Kabupaten Bogor jumlah kunjungan pasien yang menggunakan BPJS di Puskesmas Cibungbulang pada tahun 2017 yaitu sebanyak 1,864 pasien sedangkan data pasien BPJS rawat inap yang ada di Puskesmas Cibungbulang kurang lebih selama satu tahun kemarin ada 600 pasien rawat inap.

Berdasarkan penelitian terdahulu Respati (2014) bahwa ada hubungan variabel penelitian dengan mutu pelayanan kesehatan dengan kepuasan pasien di Unit Rawat Inap Puskesmas Halmahera.

Tujuan penelitian ini adalah mengetahui hubungan mutupelayanan kesehatan dengan kepuasan pasien yang menggunakan lima dimensi yaitu faktor reliability (kehandalan), responsiveness (daya tanggap), assurance (jaminan), tangible (bukti langsung), dan empaty (perhatian).

Ruang Lingkup Penelitian ini mengenai hubungan mutu pelayanan kesehatan dengan kepuasan pasien peserta BPJS di unit rawat inap Puskesmas Cibungbulang Kabupaten Bogor Tahun 2018 dengan menggunakan jenis penelitian deskriptif kuantitatif. Penelitian ini dilakukan pada bulan Agustus sampai September 2018. Penelitian dilakukan kepada 50 responden.

kesehatan dengan kepuasan pasien peserta BPJS di unir rawat inap Puskesmas Cibungbulang Kabupaten Bogor Tahun 2018. Penelitian ini dilakukan dengan mengumpulkan data menggunakan kuesioner penelitian.Populasi dalam penelitian ini adalah 1,864 pasien rawat 
inap. Sampel yang telah digunakan sebanyak 50 responden. Instrument yang digunakan pada penelitian ini adalah menggunakan kuesioner, terdiri dari pertanyaan-pertanyaan

\section{HASIL}

Data yang diperoleh dianalisa melalui komputer dengan menggunakan program Statistic Package For Sosial Science (SPSS) versi 16. Berikut hasil pengelolaan data penelitian.

Hasil analisis univariat berdasarkan faktor jenis kelamin diperoleh mayoritas adalah perempuan (52\%) sedangkan lakilaki hanya (48\%). Berdasarkan faktor umur rata-rata usia muda (68\%) sedangkan usia tua hanya (32\%).

Berdasarkan kepuasan pasien mayoritas memberikan jawaban puas sebanyak (68\%) sedangkan yang memberikan jawaban tidak puas sebanyak (38\%).

Berdasarkan faktor tangible (ketampakan fisik) yang memberikan jawaban kurang baik sebanyak (78\%) sedangkan yang memberikan jawaban baik sebanyak (22\%).Berdasarkan faktor reliability (kehandalan) yang memberikan jawaban kurang baik sebanyak (62\%) sedangkan yang memberikan jawaban baik sebanyak (38\%).

Berdasarkan faktor responsiveness untuk mendapatkan data mengenai hubungan mutu pelayanan kesehatan dengan kepuasan pasien yang menggunakan 5 (lima) dimensi.

(daya tanggap) yang memberikan jawaban kurang baik sebanyak (76\%) sedangkan yang memberikan jawaban baik sebanyak (24\%).

Berdasarkan faktor assurance (jaminan) yang memberikan jawaban kurang baik sebanyak (76\%) sedangkan yang memberikan jawaban baik sebanyak (24\%).

Berdasarkan faktor empathy (perhatian) yang memberikan jawaban kurang baik sebanyak (76\%) sedangkan yang memberikan jawaban baik sebanyak $(24 \%)$.

Dari hasil analisis bivariat (chisquare) 1-5 dapat diketahui bahwa variabel yang memiliki hubungan yang signifikan dengan kepuasan pasien adalah faktor responsiveness (daya tanggap) ( $p$-value $0,000)$ dan faktor empathy (perhatian) ( $p$ value 0,000 ). Sedangkan variabel yang tidak berhubungan dengan kepuasan pasien adalah faktor reliability (kehandalan) ( $p$-value $0,285)$, faktor tangible (kehandalan) ( $p$ value 0,125), dan faktor assurance (jaminan) (p-value 0,702).

Tabel 1. Hubungan antara Faktor Tangible (ketampakan fisik) dengan Kepuasan Pasien di Puskesmas Cibungbulang Kabupaten Bogor

\begin{tabular}{|c|c|c|c|c|c|c|c|c|}
\hline \multirow{3}{*}{$\begin{array}{c}\text { Tangible } \\
\text { (ketampakan } \\
\text { fisik) }\end{array}$} & \multicolumn{2}{|c|}{$\begin{array}{c}\text { Kepuasan } \\
\text { Pasien } \\
\end{array}$} & \multicolumn{2}{|c|}{ Total } & \multicolumn{2}{|c|}{ Total } & \multirow[t]{3}{*}{ OR } & \multirow[t]{3}{*}{ p-Value } \\
\hline & \multicolumn{2}{|c|}{ Puas } & \multicolumn{2}{|c|}{ Tidak Puas } & \multirow[b]{2}{*}{$\mathbf{N}$} & \multirow[b]{2}{*}{$\%$} & & \\
\hline & $\mathbf{N}$ & $\%$ & $\mathbf{N}$ & $\%$ & & & & \\
\hline Baik & 2 & 18,2 & 9 & 81,8 & 11 & 100,0 & 0,288 & 0,125 \\
\hline Kurang Baik & 17 & 43,6 & 22 & 56,4 & 39 & 100,0 & $\begin{array}{c}0,417- \\
1,4\end{array}$ & \\
\hline Jumlah & 19 & 38,0 & 31 & 62,0 & 50 & 100,0 & 50 & \\
\hline
\end{tabular}


Tabel 2. Hubungan antara Faktor Reliability (kehandalan) dengan Kepuasan Pasien di Puskesmas Cibungbulang Kabupaten Bogor

\begin{tabular}{|c|c|c|c|c|c|c|c|c|}
\hline \multirow[t]{3}{*}{$\begin{array}{c}\text { Reliability } \\
\text { (kehandalan) }\end{array}$} & \multicolumn{2}{|c|}{$\begin{array}{c}\text { Kepuasan } \\
\text { Pasien }\end{array}$} & \multicolumn{2}{|c|}{ Total } & \multicolumn{2}{|c|}{ Total } & \multirow[t]{3}{*}{$\mathbf{O R}$} & \multirow[t]{3}{*}{ p-Value } \\
\hline & \multicolumn{2}{|c|}{ Puas } & \multicolumn{2}{|c|}{ Tidak Puas } & & & & \\
\hline & $\mathrm{N}$ & $\%$ & $\mathrm{~N}$ & $\%$ & $\mathrm{~N}$ & $\%$ & & \\
\hline Baik & 9 & 47,4 & 10 & 52,6 & 19 & 100,0 & 1,890 & 0,285 \\
\hline Kurang Baik & 10 & 32,3 & 21 & 67,7 & 31 & 100,0 & $\begin{array}{l}1,468- \\
0,777\end{array}$ & \\
\hline Jumlah & 19 & 38,0 & 31 & 62,0 & 50 & 100,0 & & \\
\hline
\end{tabular}

Tabel 3. Hubungan antara Faktor Assurance (jaminan) dengan Kepuasan Pasien di Puskesmas Cibungbulang Kabupaten Bogor

\begin{tabular}{|c|c|c|c|c|c|c|c|c|}
\hline \multirow[t]{3}{*}{$\begin{array}{c}\text { Assurance } \\
\text { (jaminan) }\end{array}$} & \multicolumn{2}{|c|}{$\begin{array}{c}\text { Kepuasan } \\
\text { Pasien }\end{array}$} & \multicolumn{2}{|c|}{ Total } & \multicolumn{2}{|c|}{ Total } & \multirow[t]{3}{*}{ OR } & \multirow[t]{3}{*}{ p-Value } \\
\hline & \multicolumn{2}{|c|}{ Puas } & \multicolumn{2}{|c|}{ Tidak Puas } & \multirow[b]{2}{*}{$\mathrm{N}$} & \multirow[b]{2}{*}{$\%$} & & \\
\hline & $\mathrm{N}$ & $\%$ & $\mathrm{~N}$ & $\%$ & & & & \\
\hline Baik & 4 & 33,3 & 8 & 66,7 & 12 & 100,0 & 0,767 & 0,702 \\
\hline Kurang Baik & 15 & 39,5 & 23 & 60,5 & 38 & 100,0 & & \\
\hline Jumlah & 19 & 38,0 & 31 & 62,0 & 50 & 100,0 & & \\
\hline
\end{tabular}

Tabel 4. Hubungan antara Faktor Responsiveness (daya tanggap) dengan Kepuasan Pasien di Puskesmas Cibungbulang Kabupaten Bogor

\begin{tabular}{|c|c|c|c|c|c|c|c|c|}
\hline \multirow[t]{3}{*}{$\begin{array}{l}\text { Responsiveness } \\
\text { (daya tanggap) }\end{array}$} & \multicolumn{2}{|c|}{$\begin{array}{c}\text { Kepuasan } \\
\text { Pasien }\end{array}$} & \multicolumn{2}{|c|}{ Total } & \multicolumn{2}{|c|}{ Total } & \multirow[t]{3}{*}{ OR } & \multirow[t]{3}{*}{ p-Value } \\
\hline & \multicolumn{2}{|c|}{ Puas } & \multicolumn{2}{|c|}{ Tidak Puas } & \multirow[b]{2}{*}{$\mathrm{N}$} & \multirow[b]{2}{*}{$\%$} & & \\
\hline & $\mathrm{N}$ & $\%$ & $\mathrm{~N}$ & $\%$ & & & & \\
\hline Baik & 12 & 100,0 & 0 & 0 & 12 & 100,0 & 5,429 & 0,000 \\
\hline Kurang Baik & 7 & 18,4 & 31 & 81,6 & 38 & 100,0 & & \\
\hline Jumlah & 19 & 38,0 & 31 & 62,0 & 50 & 100,0 & & \\
\hline
\end{tabular}

Tabel 5. Hubungan antara Faktor Empathy (perhatian) dengan Kepuasan Pasien di Puskesmas Cibungbulang Kabupaten Bogor

\begin{tabular}{|c|c|c|c|c|c|c|c|c|}
\hline \multirow[t]{3}{*}{$\begin{array}{c}\text { Empathy } \\
\text { (perhatian) }\end{array}$} & \multicolumn{2}{|c|}{$\begin{array}{c}\text { Kepuasan } \\
\text { Pasien }\end{array}$} & \multicolumn{2}{|c|}{ Total } & \multicolumn{2}{|c|}{ Total } & \multirow[t]{3}{*}{ OR } & \multirow[t]{3}{*}{ p-Value } \\
\hline & \multicolumn{2}{|c|}{ Puas } & \multicolumn{2}{|c|}{ Tidak Puas } & & & & \\
\hline & $\mathrm{N}$ & $\%$ & $\mathrm{~N}$ & $\%$ & $\mathrm{~N}$ & $\%$ & & \\
\hline Baik & 12 & 100,0 & 0 & 0 & 12 & 100,0 & 5,429 & 0,000 \\
\hline Kurang Baik & 7 & 18,4 & 31 & 81,6 & 38 & 100,0 & & \\
\hline Jumlah & 19 & 38,0 & 31 & 62,0 & 50 & 100,0 & & \\
\hline
\end{tabular}

\section{PEMBAHASAN}

Berdasarkan tabel 1, diperoleh bahwa tidak ada hubungan antara faktor tangible dengan kepuasan pasiendisebabkan oleh fasilitas fisik seperti, ruang rawat inap dan peralatan yang digunakan. Ruang rawat inap belum tertata rapi sehingga menyebabkan 
kurang nyamannya yang dirasakan oleh pasien, selain itu peralatan yang kurang memadai sehingga pasien menggunakan fasilitas kesehatan yang lain yang memiliki peralatan lebih memadai. Hasil tersebut menjadi alasan tidak adanya hubungan yang signifikan antara faktor tangible (ketampakan fisik) dengan kepuasan pasien.

Berdasarkan tabel 2, diperoleh bahwa tidak ada hubungan antara faktor reliability dengan kepuasan pasien disebabkan oleh kemampuan memberikan pelayanan yang sesuai secara akurat dan terpercaya, sikap simpatik dan dengan akurasi yang tinggi kepada para pasien. Dapat diukur dengan tindakan pelayanan yang akurat oleh tenaga medis, melayani dengan baik dan ramah saat melakukan pengobatan dan perawatan, memberikan pelayanan dengan tepat dan benar sesuai dengan prosedur yang ditetapkan.

Berdasarkan tabel 3, diperoleh bahwa tidak ada hubungan antara faktor assurance (jaminan) dengan kepuasan pasien disebabkan oleh keramahan petugas yang memberikan pelayanan yang membuat rasa nyaman kepada responden, kesopanan petugas.

\section{KESIMPULAN}

Berdasarkan hasil penelitian yang dilakukan terhadap 50 responden di Puskesmas Cibungbulang Kabupaten Bogor di peroleh bahwa Tidak terdapat hubungan antara faktor tangible (bukti langsung) dengan kepuasan pasien di unit rawat inap di UPT Puskesmas Cibungbulang Kabupaten Bogor. Dengan p-value 0,125> $\alpha(0,05)$.

Tidak terdapat hubungan antara faktor reliability (kehandalan) dengan kepuasan pasien di unit rawat inap di UPT Puskesmas Cibungbulang Kabupaten Bogor. Dengan pvalue $0,285>\alpha(0,05)$

Tidak terdapat hubungan antara faktor
Berdasarkan tabel 4, Hasil penelitian menyatakan bahwa ada hubungan antara faktor responsiveness (daya tanggap) dengan kepuasan pasien disebabkan oleh tidak memuaskannya pelayanan kesehatan memberikan rujukan berjenjang, kurangnya informasi petugas pelayanan kesehatan kepada responden mengenai sistem pelayanan kesehatan. Hasil uji statistik chi square diperoleh nilai $p$-value $=0,000$ ( $>0,05)$ yang menyatakan Ho ditolak.

Berdasarkan tabel 5, dari hasil analisis yang dilakukan peneliti berdasarkan faktor empathy (perhatian) dengan kepuasan pasien diketahui bahwa responden yangmemiliki persepsi baik dan puas terhadap mutu pelayanan dalam dimensi empathy (perhatian) ada sebanyak 12 orang (100\%), sedangkan responden yang memiliki persepsi baik tapi tidak puas ada sebanyak 0 orang (0\%). Responden yang memiliki persepsi kurang baik tapi puas sebanyak 7 orang $(18,4 \%)$, sedangkan responden yang memiliki persepsi kurang baik tapi tidak puas ada sebanyak 31 orang $(81,6 \%)$. Hasil uji statistik chi square diperoleh nilai $p$ value $=0,000(\mathrm{p}>0,05)$ yang menyatakan Ho ditolak.

assurance (jaminan) dengan kepuasan pasien di unit rawat inap di UPT Puskesmas Cibungbulang Kabupaten Bogor. Dengan pvalue $0,702>\alpha(0,05)$.

Terdapat hubungan antara faktor responsiveness (daya tanggap) dengan kepuasan pasien di unit rawat inap di UPT Puskesmas Cibungbulang Kabupaten Bogor. Dengan p-value $0,000<\alpha(0,05)$.

Terdapat hubungan antara faktor empathy (pethatian) dengan kepuasan pasien di unit rawat inap di UPT Puskesmas Cibungbulang Kabupaten Bogor. Dengan pvalue $0,000<\alpha(0,05)$. 


\section{DAFTAR PUSTAKA}

[1] Azwar, Azrul. (2010). Pengantar Administrasi Kesehatan. Edisi Ketiga. Jakarta : PT. Binarupa Aksara.

[2] Bustami. (2011). Penjamin Mutu Pelayanan Kesehatan dan Akseptabilitasnya. Jakarta : Erlangga.

[3] BPJS Kesehatan. (2014). Peraturan BPJS Kesehatan Nomor 1 Tahun 2014. BPJS Kesehatan.

[4] Dapartemen Kesehatan RI. (2006). Pedoman Manajemen Sumber Daya Manusia (SDM) Kesehatan. Jakarta

[5] Dinas Kesehatan Kabupaten Bogor. (2017).Laporan Tahunan UPT Puskesmas Cibungbulang Tahun 2017. Bogor : UPT Puskesmas Cibungbulang.

[6] Effendi \& Makhfudli. (2015). Keperawatan Kesehatan Komunitas. Salemba Medika. : Jakarta.

[7] Farich, H. Achmad. (2012). Manajemen Pelayanan Kesehatan Masyarakat. Yogyakarta: Gosyen Publishing

[8] Hidayat. A. AA. (2013). Metode Penelitian Keperawatan dan Teknik Analisis Data. Jakarta : Salemba Medika.

[9] Jacobalis, Samsi. (2000). Menjaga Mutu Pelayanan Rumah Sakit. Jakarta : PT Citra Windu Satria.

[10] Kementrian Kesehatan RI. (2003). Standar Pelayanan Minimal Bidang Kesehatan Kabupaten/Kota (Kepmenkes RI nomor1457/ Menkes/SK/X/2003). Jakarta : Kementrian Kesehatan

[11] Kementrian Kesehatan Republik Indonesia. 2013. Pedoman Penyelenggaraan Puskesmas Mampu Poned.Jakarta : Menkes RI : 2013.

[12] Maulidian, Fadilah. (2017). Faktorfaktor yang berhubungan dengan persepsi pasien terhadap mutu di UPTD Puskesmas Cigudeg Kabupaten Bogor Tahun 2017. Skripsi. UIKA,Bogor.
[13] Machfoedz, Ircham. (2013). Metodologi Penelitian Kuantitatif \& Kualitatif . Yogyakarta : Fitramaya.

[14] Muninjaya, A. A. Gde. (2013). Manajemen Mutu Pelayanan Kesehatan.Jakarta : Penerbit Buku Kedokteran EGC.

[15] Mubarrak, Wahit Iqbal. (2012). Ilmu Kesehatan Masyarakat : Konsep dan aplikasi kebidanan. Jakarta : Salemba Mediaka.

[16] Mukti, Ali Ghufron. (2007). Strategi Terkini Peningkatan Mutu Pelayanan Kesehatan : Konsep Implementasi. Yogyakarta : PT. Karya Husada Mukti.

[17] Ningrum, Rinda Mustika. (2014). Hubungan Mutu Pelayanan Kesehatan BPJS Dengan Kepuasan Pasien. Skripsi.

[18] Notoatmodjo, Soekidjo. 2010. Metodologi Penelitian Kesehatan Edisi Revisi. Jakarta : Rineka Cipta.

[19] Nursalam. 2014. Manajemen Keperawatan : Aplikasi dalam Praktik Keperawatan Profesional Edisi 4. Jakarta Salemba Medika

[20] Ojah. (2017). Faktor-faktor yang berhubungan dengan kualitas pelayanan kesehatan di Puskesmas Puraseda Kecamatan Leuwiliang Kabupaten Bogor 2017. Skripsi. UIKA,Bogor.

[21] Pohan, Imbalo S. (2006). Jaminan Mutu Pelayanan Kesehatan, Dasar-dasar Pengertian. Jakarta : Kesaint Blanc.

[22] Peraturan Menteri Kesehatan Republik Indonesia tentang Pelayanan Kesehatan pada Jaminan Kesehatan (Permenkes Nomor 71 Tahun 2013). Jakarta : Kementrian Kesehatan.

[23] Profil Kesehatan Indonesia Tahun 2016. Jakarta : Kementrian Kesehatan RI 2016.

[24] Peraturan Menteri Kesehatan Republik 
Indonesia tentang Pusat Kesehatan Masyarakat. (Permenkes RI Nomor 75 Tahun 2014). Jakarta: Kementrian Kesehatan.

[25] Respati, Shinta Ayu. ( 2015). Hubungan Mutu Pelanan Kesehatan dengan Tingkat Kepuasan Pasien Rawat Inap di Puskesmas Halmahera Kota Semarang tahun 2014. Skripsi.

[26] Ratnawati, Lina. (2015). Hubungan Antara Persepsi Mutu Pelayanan Dengan Tingkat Kepuasan Pasien KIA Puskesmas Ngesrep Kota Semarang. Skripsi. Semarang : UNNES.

[27] Republik Indonesia. (2011). Undangundang RI Nomor 24 Tahun 2011 tentang Badan Penyelenggara Jaminan Sosial. Jakarta : Kementrian Kesehatan

[28] Republik Indonesia. (2009). Undangundang RI Nomor 36 Tahun 2009 tentang Kesehatan. Jakarta : Kementrian Kesehatan

[29] Republik Indonesia. (2014). UndangUndang RI Nomor 75 Tahun 2014 tentang Puskesmas. Jakarta : Permenkes RI.

[30] Ririn. (2011). Faktor-faktor yang berhubungan dengan kepuasan pasien terhadap pelayanan kepuasan pasien terhadap pelayanan kesehatan di Puskesmas Halmahera Kota Semarang Tahun 2011. Skripsi.Universitas Negeri Semarang.Skripsi.Universitas Negeri Semarang.

[31] Rizkyani, Ria. (2016). Faktor-Faktor Yang Berhubungan Dengan Persepsi Pasien Terhadap Kualitas Pelayanan
Rawat Jalan di Rumah Sakit Siaga Raya Jakarta Selatan. Skripsi. Jakarta : UEU.

[32] Sari, Nirmala. (2014). Hubungan Mutu Pelayanan Keperawatan Dengan Kepuasan Pasien Pengguna BPJS Di Puskesmas Mojowarno Kabupaten Jombang. Skripsi. Jember : FKM Universitas jember.

[33] Suaib. (2013). Pengaruh Kualitas Pelayanan Terhadap Kepuasan Pasien Pada Ruang Rawat Inap RSUD Syech Yusuf Kabupaten Gowa. Jurnal. Makasar : FKM- Universitas Hasanudin Makasar.

[34] Syaputra, D. Agus. (2015). Hubungan Mutu Pelayanan BPJS Kesehatan Dengan Kepuasan Pasien Di InstalasiRawat Inap Kelas II Rumah Sakit Umum Daerah. Skripsi.

[35] Sugiyono, (2010). Metode Penelitian Pendidikan Kuantitatif, Kualitatif, dan R\&D. Bandung: PT. Alfabeta

[36] Suharsimi Arikunto, (2006). Prosedur Penelitian Suatu Pendekatan Praktik. Jakarta: PT.Asdi Mahasatya

[37] Vianti, Novita Resha. (2016) Analisis Kepuasan Pasien BPJS (Badan Penyelenggara Jaminan Sosial) terhadap pelayanan kesehatan di Instalasi Rawat Inap ( IRI ) Bangsal Dahlia RSUD Ungaran. Skripsi.

[38] WHO.(2008). The World Health Report 2008 : Primary Health Care Now More Than Ever. Geneva, Switzerland : Author 